\title{
$\alpha, \omega$-Cholesterol-Functionalized Low Molecular Weight Polyethylene Glycol as a Novel Modifier of Cationic Liposomes for Gene Delivery
}

\author{
Cui-Cui Ma ${ }^{1, \dagger}$, Zhi-Yao He ${ }^{1, \dagger}$, Shan Xia ${ }^{1,2}$, Ke Ren ${ }^{3}$, Li-Wei Hui ${ }^{1}$, Han-Xiao Qin ${ }^{1}$, \\ Ming-Hai Tang ${ }^{1}$, Jun Zeng ${ }^{1, *}$ and Xiang-Rong Song ${ }^{1, *}$
}

1 Department of Anesthesiology, State Key Laboratory of Biotherapy, West China Hospital, Sichuan University, Chengdu 610041, Sichuan, China; E-Mails: ccma2012@126.com (C.-C.M.); heyaode@163.com (Z.-Y.H.); xiashanshan@sina.com (S.X.); huiliwei.love@163.com (L.-W.H.); qin_hanxiao@163.com (H.-X.Q.); tangminghai1982@126.com (M.-H.T.)

2 Central Laboratory, Science Education Department, Chengdu Normal University, Chengdu 610041, Sichuan, China

3 Department of Pharmaceutical Sciences, University of Nebraska Medical Center, Omaha, NE 68198, USA; E-Mail: renkemallee@gmail.com

$\dagger$ These authors contributed equally to this work.

* Authors to whom correspondence should be addressed;

E-Mails: junzengscu@163.com (J.Z.); songxr@scu.edu.cn (X.-R.S.);

Tel./Fax: +86-28-8550-3817 (J.Z. \& X.-R.S.).

External Editor: Gregor Drummen

Received: 28 August 2014; in revised form: 25 September 2014 / Accepted: 30 September 2014 / Published: 6 November 2014

\begin{abstract}
Here, three novel cholesterol (Ch)/low molecular weight polyethylene glycol (PEG) conjugates, termed $\alpha, \omega$-cholesterol-functionalized PEG $\left(\mathrm{Ch}_{2}-\mathrm{PEG}_{\mathrm{n}}\right)$, were successfully synthesized using three kinds of PEG with different average molecular weight (PEG600, $\mathrm{PEG}_{1000}$ and $\mathrm{PEG}_{2000}$ ). The purpose of the study was to investigate the potential application of novel cationic liposomes $\left(\mathrm{Ch}_{2}-\mathrm{PEG}_{\mathrm{n}}-\mathrm{CLs}\right)$ containing $\mathrm{Ch}_{2}-\mathrm{PEG}_{\mathrm{n}}$ in gene delivery. The introduction of $\mathrm{Ch}_{2}-\mathrm{PEG}_{\mathrm{n}}$ affected both the particle size and zeta potential of cationic liposomes. $\mathrm{Ch}_{2}-\mathrm{PEG}_{2000}$ effectively compressed liposomal particles and $\mathrm{Ch}_{2}-\mathrm{PEG}_{2000}-\mathrm{CLs}$ were of the smallest size. $\mathrm{Ch}_{2}-\mathrm{PEG}_{1000}$ and $\mathrm{Ch}_{2}-\mathrm{PEG}_{2000}$ significantly decreased zeta potentials of $\mathrm{Ch}_{2}-\mathrm{PEG}_{\mathrm{n}}-\mathrm{CLs}$, while $\mathrm{Ch}_{2}-\mathrm{PEG}_{600}$ did not alter the zeta potential due to the
\end{abstract}


short PEG chain. Moreover, the in vitro gene transfection efficiencies mediated by different $\mathrm{Ch}_{2}-\mathrm{PEG}_{\mathrm{n}}-\mathrm{CLs}$ also differed, in which $\mathrm{Ch}_{2}-\mathrm{PEG} 600-\mathrm{CLs}$ achieved the strongest GFP expression than $\mathrm{Ch}_{2}-\mathrm{PEG}_{1000}-\mathrm{CLs}$ and $\mathrm{Ch}_{2}-\mathrm{PEG}_{2000} \mathrm{CLs}$ in SKOV-3 cells. The gene delivery efficacy of $\mathrm{Ch}_{2}-\mathrm{PEG}_{\mathrm{n}}-\mathrm{CLs}$ was further examined by addition of a targeting moiety (folate ligand) in both folate-receptor (FR) overexpressing SKOV-3 cells and A549 cells with low expression of FR. For $\mathrm{Ch}_{2}-\mathrm{PEG}_{1000}-\mathrm{CLs}$ and $\mathrm{Ch}_{2}-\mathrm{PEG}_{2000}-\mathrm{CLs}$, higher molar ratios of folate ligand resulted in enhanced transfection efficacies, but $\mathrm{Ch}_{2}-\mathrm{PEG}_{600}-\mathrm{CLs}$ had no similar in contrast. Additionally, MTT assay proved the reduced cytotoxicities of cationic liposomes after modification by $\mathrm{Ch}_{2}-\mathrm{PEG}_{\mathrm{n}}$. These findings provide important insights into the effects of $\mathrm{Ch}_{2}-\mathrm{PEG}_{n}$ on cationic liposomes for delivering genes, which would be beneficial for the development of $\mathrm{Ch}_{2}-\mathrm{PEG}_{\mathrm{n}}-\mathrm{CLs}$-based gene delivery system.

Keywords: cholesterol; polyethylene glycol; cationic liposomes; gene delivery; folate ligand

\section{Introduction}

Cholesterol (Ch), an essential membrane component in higher eukaryotes, modulates functions of membrane proteins and participates in several membrane trafficking and transmembrane signaling processes [1]. Ch facilitates the formation of semi-permeable barriers between cellular compartments and regulates membrane fluidity [1,2]. Ch has been widely used for liposome preparation and other lipid-based drug delivery systems [3,4]. Furthermore, the hydroxyl group in Ch can be modified with other moieties [5,6]. Poly (ethylene glycol) (PEG) cholesterol conjugates (PEG-Ch) had been developed to enhance the stability and activity of liposomes and other lipid-based drug delivery systems [7-9]. PEG-Ch conjugates were further modified with targeting ligands or antibodies to increase the targeting efficacy of the delivery systems [10-12].

As a PEG-Ch conjugate, it has been reported that the hydrophobic groups in $\alpha, \omega$-Ch-modified PEG $\left(\mathrm{Ch}_{2}-\mathrm{PEG}_{\mathrm{n}}\right)$ were capable of inserting into the hydrophobic interior of lipid bilayers or membranes [13-15]. High molecular weight $\mathrm{Ch}_{2}-\mathrm{PEG}_{\mathrm{n}}\left(\mathrm{PEG}_{30000}-\mathrm{PEG}_{35000}\right.$ ) had been used to prepare liposome gels [16,17] and core-shell emulsion particles [18]. However, there is no report about applying $\mathrm{Ch}_{2}-\mathrm{PEG}_{\mathrm{n}}$ to gene delivery up to now.

For PEG conjugates, the molecular weight of PEG had a significant effect on the properties of the

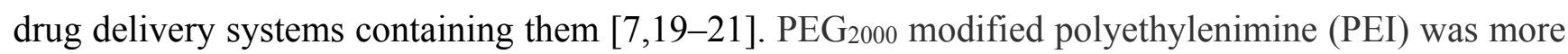
efficient than PEG5000 modified PEI as evaluated by in vitro gene transfer [22]. PEG400 significantly enhanced fractional laser-assisted drug delivery when compared with PEG $_{2050}$ and PEG3350 [23].

Therefore, the purpose of the study was to explore the potential application of novel cationic liposomes $\left(\mathrm{Ch}_{2}-\mathrm{PEG}_{\mathrm{n}}-\mathrm{CLs}\right.$ ) containing $\mathrm{Ch}_{2}-\mathrm{PEG}_{\mathrm{n}}$ using three kinds of $\mathrm{PEG}$ with different average molecular weight (PEG600, $\mathrm{PEG}_{1000}$ and $\mathrm{PEG}_{2000}$ ) for gene delivery. The impacts of variation in PEG molecular weight on the properties, toxicities and gene delivery efficacies were determined. In addition, the gene delivery efficacy of $\mathrm{Ch}_{2}-\mathrm{PEG}_{n}-\mathrm{CLs}$ was further investigated by introduction of the targeting moiety (folate ligand) in both folate-receptor (FR) overexpressing SKOV-3 cells and A549 cells with low expression of FR. 


\section{Results and Discussion}

\subsection{Synthesis and Identification of $\mathrm{Ch}_{2}-P E G_{n}$}

The successful synthesis of $\mathrm{Ch}_{2}-\mathrm{PEG}_{\mathrm{n}}$ was confirmed by ${ }^{1} \mathrm{H}-\mathrm{NMR}$ and mass spectra. As shown in Scheme $1, \mathrm{Ch}_{2}-\mathrm{PEG}_{\mathrm{n}}$ was synthesized by esterification of succinic anhydride-cholesterol (suc-Ch) with PEG using 4-dimethylaminopyridine (DMAP) and 1-ethyl-3-(3-dimethyllaminopropyl) carbodiimide hydrochloride (EDCI) as catalysts. The ${ }^{1} \mathrm{H}-\mathrm{NMR}$ spectra of $\mathrm{Ch}_{2}-\mathrm{PEG}_{\mathrm{n}}$ were shown in Figure $1 \mathrm{~A}$. The principal peaks of suc-Ch and poly (ethylene glycol) (PEG) moieties were observed [8,24]. The molecular weights of $\mathrm{Ch}_{2}-\mathrm{PEG}_{\mathrm{n}}$ were measured by the Quadrupole-Time of Flight (Q-TOF) mass spectra as shown in Figure 1B. For $\mathrm{Ch}_{2}-\mathrm{PEG}_{600}$ and $\mathrm{Ch}_{2}-\mathrm{PEG}_{1000}$, the mass-to-charge ratio $(\mathrm{m} / \mathrm{z})$ spectrums showed dominant ions at $m / z 1545$ and 1896 . Their $m / z$ ions were singly charged $\left[(\mathrm{M}+\mathrm{H})^{+}\right]$. Therefore, the measured molecular weight of $\mathrm{Ch}_{2}-\mathrm{PEG}_{600}$ and $\mathrm{Ch}_{2}-\mathrm{PEG}_{1000}$ were 1544 and $1895 \mathrm{Da}$ respectively after subtracting $\mathrm{H}^{+}$. For $\mathrm{Ch}_{2}-\mathrm{PEG}_{2000}$, the $m / z$ values differed by $0.5 \mathrm{Da}$ as $\mathrm{z}$, so the number of charges was equal to 2 . The $m / z$ ions were doubly charged $\left[(\mathrm{M}+2 \mathrm{H})^{2+}\right]$. The measured molecular weight of $\mathrm{Ch}_{2}-\mathrm{PEG}_{2000}$ was $3012 \mathrm{Da}[(1508-2) \times 2]$. All the calculated molecular weights were consistent with the true molecular weights.

The melting points and appearances of $\mathrm{Ch}_{2}-\mathrm{PEG}_{\mathrm{n}}$ were summarized in Table 1. Three kinds of $\mathrm{Ch}_{2}-\mathrm{PEG}_{\mathrm{n}}$ had different melting points, which might impact the film-forming property of the mixed lipids and therefore influence the stability of cationic liposomes.

Scheme 1. Synthesis route of $\mathrm{Ch}_{2}-\mathrm{PEG}_{\mathrm{n}}$ conjugates.

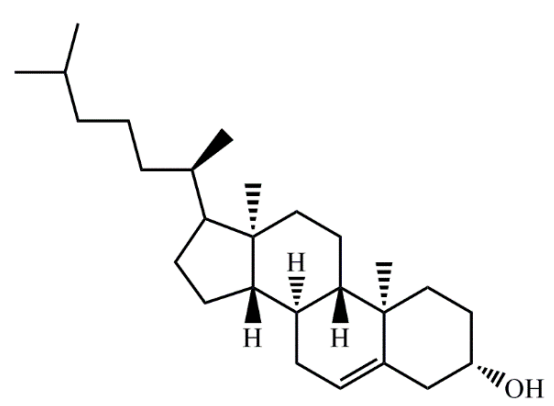

Chol

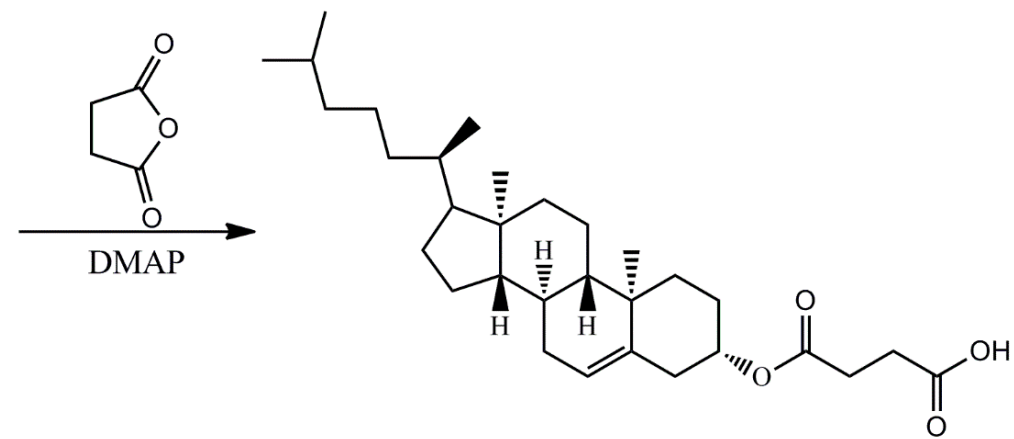

suc-Chol

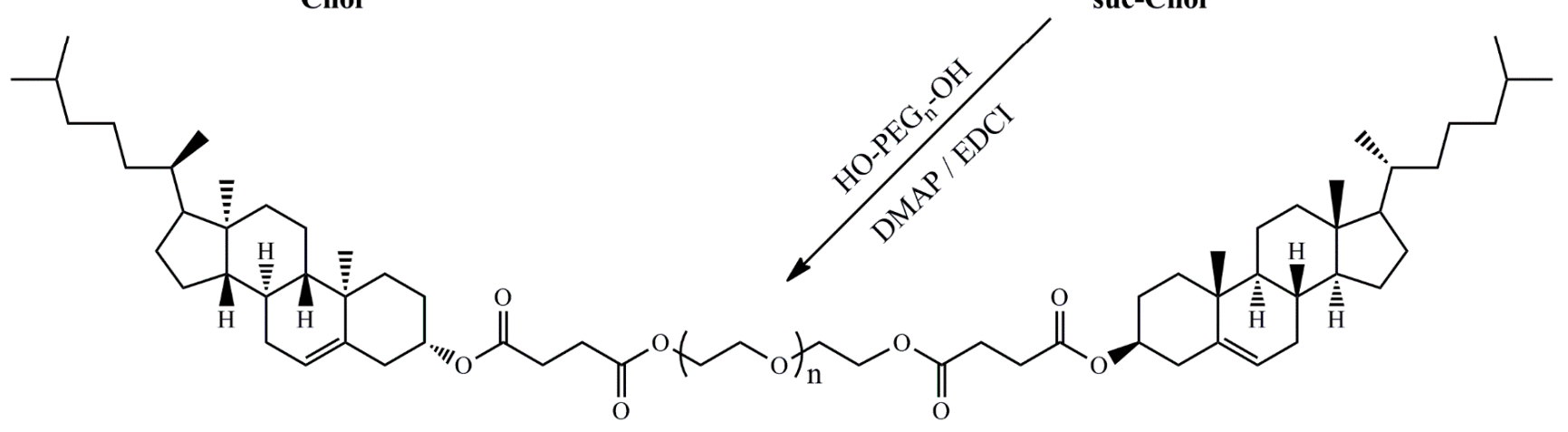

$\mathrm{Ch}_{2}-\mathrm{PEG}_{\mathbf{n}}$ 
Figure 1. ${ }^{1} \mathrm{H}-\mathrm{NMR}$ and mass spectra of $\mathrm{Ch}_{2}-\mathrm{PEG}_{\mathrm{n}}$. (A) ${ }^{1} \mathrm{H}-\mathrm{NMR}$ spectra $(400 \mathrm{MHz}$ ) of $\mathrm{Ch}_{2}-\mathrm{PEG}_{\mathrm{n}}$ in $\mathrm{CDCl}_{3}$; $(\mathbf{a}, \mathbf{b})$ 6- and 3-position protons in Chol; (c) protons of methylene in PEG and (d) methylene proton of succinyl group. The principal proton peaks of Chol-suc and PEG were found in $\mathrm{Ch}_{2}-\mathrm{PEG}_{n}$; (B) Mass spectra of $\mathrm{Ch}_{2}-\mathrm{PEG}_{n}$. The $m / z$ ions of $\mathrm{Ch}_{2}-\mathrm{PEG}_{600}$ and $\mathrm{Ch}_{2}-\mathrm{PEG}_{1000}$ are singly charged molecular-related ions; the $\mathrm{m} / z$ ions of $\mathrm{Ch}_{2}-\mathrm{PEG}_{2000}$ are doubly charged molecular-related ions. The measured molecular weight of $\mathrm{Ch}_{2}-\mathrm{PEG}_{600}$, $\mathrm{Ch}_{2}-\mathrm{PEG}_{1000}$ and $\mathrm{Ch}_{2}-\mathrm{PEG}_{2000}$ were 1544, 1895 and 3012 Da, respectively.

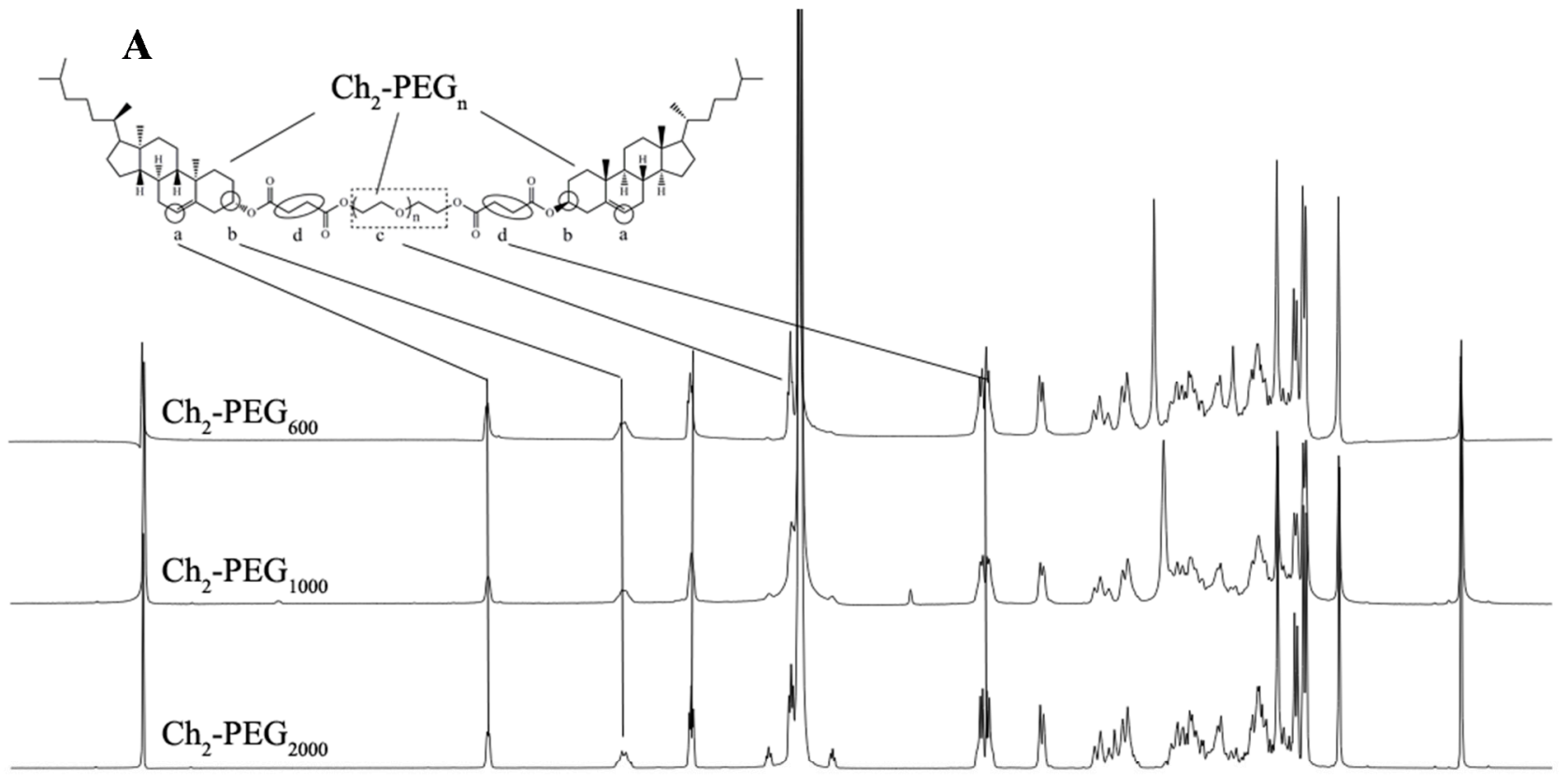

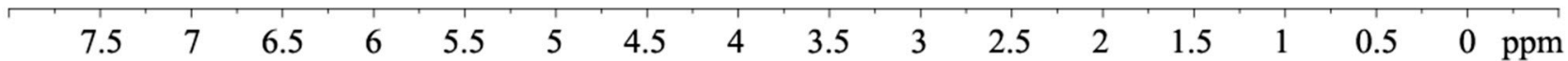
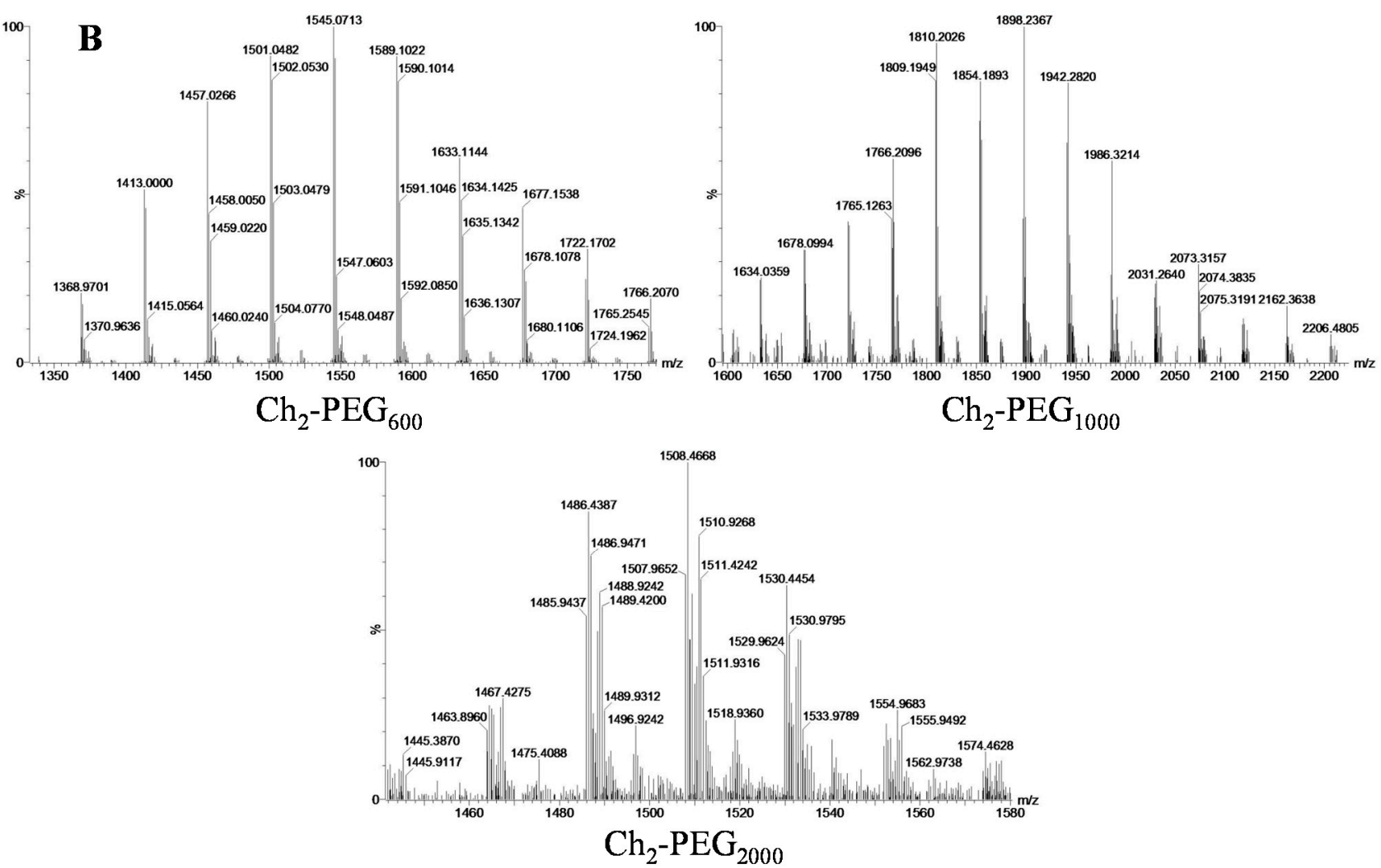
Table. 1. The melting points and appearances of $\mathrm{Ch}_{2}-\mathrm{PEG}_{\mathrm{n}}$. The melting point was recorded as the midpoint value in the melting temperature range to facilitate comparison.

\begin{tabular}{ccc}
\hline Samples & Melting Point $\left({ }^{\circ} \mathbf{C}\right)$ & Appearance $\left(25{ }^{\circ} \mathbf{C}\right)$ \\
\hline $\mathrm{PEG}_{600} \rightarrow \mathrm{Ch}_{2}-\mathrm{PEG}_{600}$ & $20 \rightarrow 33(\uparrow)$ & Clear liquid $\rightarrow$ Clear semi-solid \\
$\mathrm{PEG}_{1000} \rightarrow \mathrm{Ch}_{2}-\mathrm{PEG}_{1000}$ & $33 \rightarrow 40(\uparrow)$ & White paste $\rightarrow$ Clear solid \\
$\mathrm{PEG}_{2000} \rightarrow \mathrm{Ch}_{2}-\mathrm{PEG}_{2000}$ & $52 \rightarrow 47.5(\downarrow)$ & White flake $\rightarrow$ White powder \\
\hline
\end{tabular}

\subsection{Physicochemical Properties of $\mathrm{Ch}_{2}-P E G_{n}-C L s$}

The particle size and polydispersity index (PDI) of $\mathrm{Ch}_{2}-\mathrm{PEG}_{\mathrm{n}}-\mathrm{CLs}$ were shown in Figure $2 \mathrm{~A}$. There were no significant differences of the particle size and PDI when comparing $\mathrm{Ch}_{2}-\mathrm{PEG}_{600}-\mathrm{CLs}$ and $\mathrm{Ch}_{2}-\mathrm{PEG}_{1000}-\mathrm{CLs}$ with mPEG-CLs (CLs modified by mPEG $2000-$ suc-Ch). However, the particle size of $\mathrm{Ch}_{2}-\mathrm{PEG}_{2000}-\mathrm{CLs}(74 \mathrm{~nm})$ was significantly smaller than those of $\mathrm{Ch}_{2}-\mathrm{PEG}_{600}-\mathrm{CLs}$ and $\mathrm{Ch}_{2}-\mathrm{PEG}_{1000}-\mathrm{CLs}(p<0.05)$. It was considered that the size decrease of $\mathrm{Ch}_{2}-\mathrm{PEG}_{2000}-\mathrm{CLs}$ might be attributed to the introduction of $\mathrm{Ch}_{2}-\mathrm{PEG}_{2000}$, which anchored into the liposomal bilayer by $\mathrm{Ch}$ segments $[25,26]$ and extended the PEG chain on the surface of the liposome. The PEG chain compressed the liposomal particle [22], and therefore reduced the particle size. Then the effect of $\mathrm{Ch}_{2}-\mathrm{PEG}_{2000}$ on particle size was further studied. As shown in Figure 2B, the particle size of $\mathrm{Ch}_{2}-\mathrm{PEG}_{2000}$-CLs gradually decreased with a higher polydispersity when the molar ratio of $\mathrm{Ch}_{2}-\mathrm{PEG}_{2000}$ increased. Due to the high curvature and micellar preference of the large hydrophilic PEG chain, it was challenging to stably integrate high molar ratio $\mathrm{Ch}_{2}-\mathrm{PEG}_{n}$ into liposomal bilayer [27]. Therefore, $5 \mathrm{~mol} \% \mathrm{Ch}_{2}-\mathrm{PEG}_{2000}$ was the optimal molar ratio.

The zeta potentials of $\mathrm{Ch}_{2}-\mathrm{PEG}_{1000}-\mathrm{CLs}$ and $\mathrm{Ch}_{2}-\mathrm{PEG}_{2000}-\mathrm{CLs}$ were significantly lower than that of $\mathrm{Ch}_{2}-\mathrm{PEG} 600-\mathrm{CLs}$ as seen in Figure $2 \mathrm{C}(p<0.001)$. It suggested that $\mathrm{Ch}_{2}-\mathrm{PEG}_{1000}$ and $\mathrm{Ch}_{2}-\mathrm{PEG}_{2000}$ could shield the electric charge of cationic liposomes. Therefore, they were good candidates like $\mathrm{mPEG}_{2000}$-suc-Ch for preparing long-circulating or stealth liposomes. The zeta potential of $\mathrm{Ch}_{2}$-PEG600-CLs was close to CLs (Figure 2C), which was consistent with the previous report that low molecular weight PEG did not effectively shield the positive charge of cationic particles [19]. The potential impact of molar ratio of $\mathrm{Ch}_{2}-\mathrm{PEG}_{2000}$ on zeta potentials was also studied. As shown in Figure 2D, $15 \mathrm{~mol} \%$ was the most efficient ratio in reducing zeta potential. Similar zeta potential values were found with 5 and $10 \mathrm{~mol} \% \mathrm{Ch}_{2}-\mathrm{PEG}_{2000}$. 
Figure 2. Particle size, PDI and zeta potential of $\mathrm{Ch}_{2}-\mathrm{PEG}_{n}-\mathrm{CLs}$ (Mean $\pm \mathrm{SD}, n=3$, $* p<0.05, * * * p<0.001)$. (A,C) Particle size, PDI, and zeta potential of $\mathrm{Ch}_{2}-\mathrm{PEG}_{\mathrm{n}} \mathrm{CLs}$, CLs (normal cationic liposomes without PEG introduction) and mPEG-CLs; (B,D) The effect of molar ratio of $\mathrm{Ch}_{2}-\mathrm{PEG}_{2000}$ on the particle size, PDI and zeta potential of $\mathrm{Ch}_{2}-\mathrm{PEG} 2000-\mathrm{CLS}$.
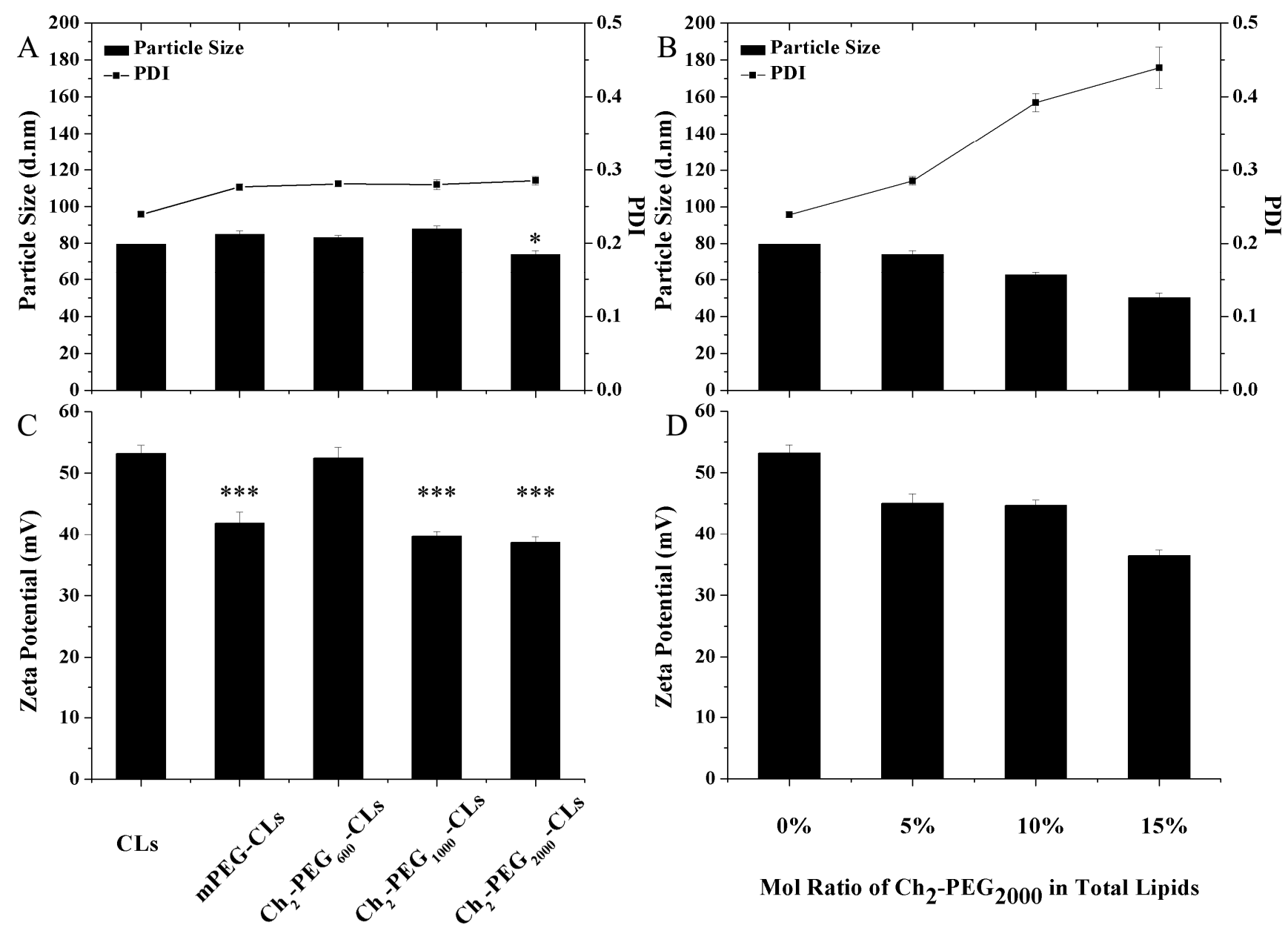

\subsection{Gene Transfection Efficiencies of $\mathrm{Ch}_{2}-P E G_{n}-C L s$}

Different types of cationic liposomes were evaluated in gene transfection efficiencies by comparison. As shown in Figure 3, $\mathrm{Ch}_{2}-\mathrm{PEG}_{600}-\mathrm{CLs}$ had slightly higher transfection efficiency than CLs and mPEG-CLs, but there were no significant differences. In contrast, the transfection efficiencies of $\mathrm{Ch}_{2}-\mathrm{PEG}_{1000}-\mathrm{CLs}$ and $\mathrm{Ch}_{2}-\mathrm{PEG}_{2000}-\mathrm{CLs}$ were significantly lower than that of $\mathrm{Ch}_{2}-\mathrm{PEG}_{600}-\mathrm{CLs}(p<0.001)$. The higher zeta potential of $\mathrm{Ch}_{2}-\mathrm{PEG}_{600}-\mathrm{CLs}$ (Figure 2C) than the other $\mathrm{Ch}_{2}-\mathrm{PEG}_{\mathrm{n}}-\mathrm{CLs}$ might be due to its high transfection efficiency. Therefore, zeta potential is an important parameter when applying $\mathrm{Ch}_{2}-\mathrm{PEG}_{\mathrm{n}}$ to gene delivery. $\mathrm{Ch}_{2}-\mathrm{PEG}_{2000}-\mathrm{CLs}$, with the same zeta potential but the smaller particle size (Figure 2A), achieved a bit higher transfection efficiency than $\mathrm{Ch}_{2}-\mathrm{PEG}_{1000}-\mathrm{CLs}$. 
Figure 3. Transfection efficiency and fluorescence images $(200 \times)$ of $\mathrm{Ch}_{2}-\mathrm{PEG}_{\mathrm{n}}-\mathrm{CLs}$ (mean $\pm \mathrm{SD}, n=3, * * * p<0.001$ ).
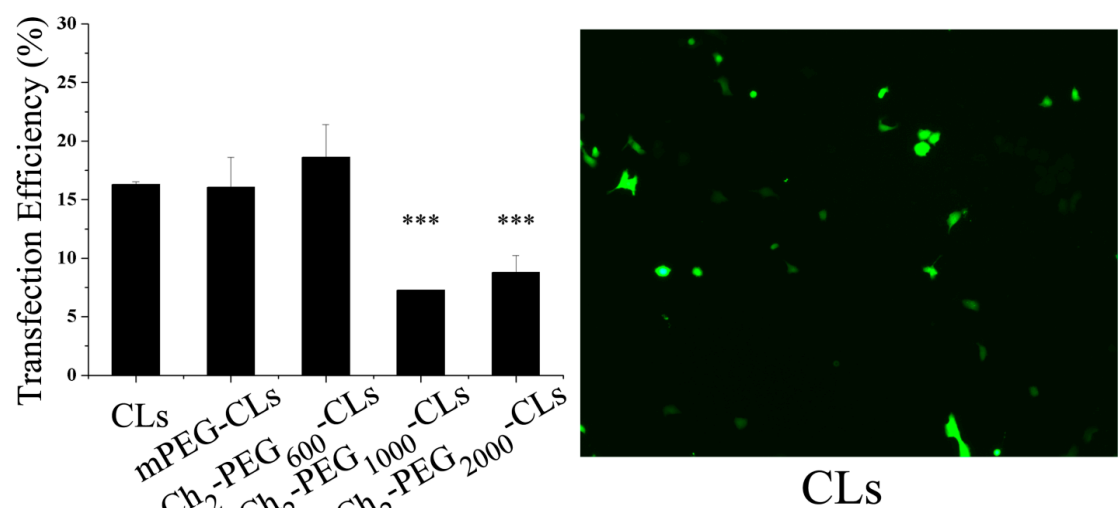

CLs

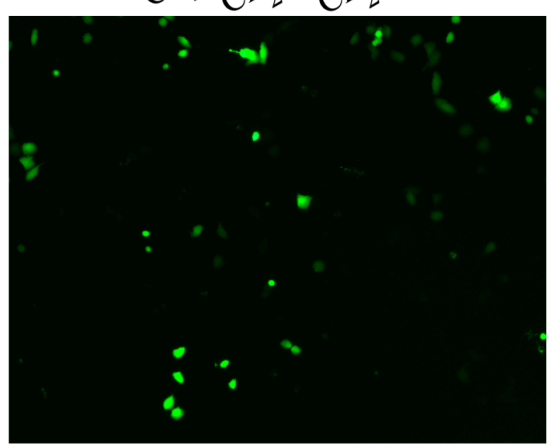

$\mathrm{Ch}_{2}-\mathrm{PEG}_{600}-\mathrm{CLs}$

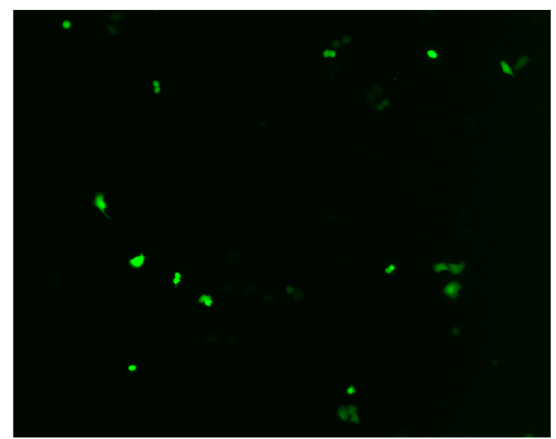

$\mathrm{Ch}_{2}-\mathrm{PEG}_{1000}-\mathrm{CLs}$

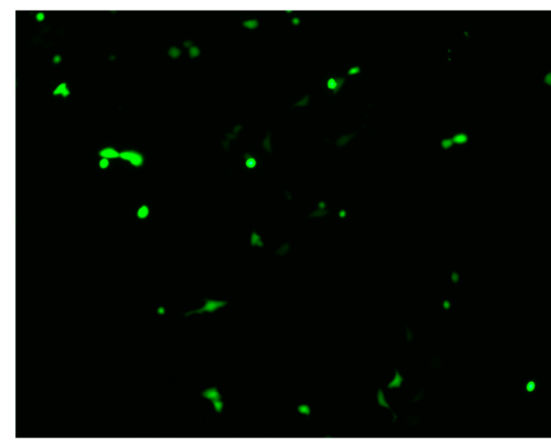

mPEG-CLs

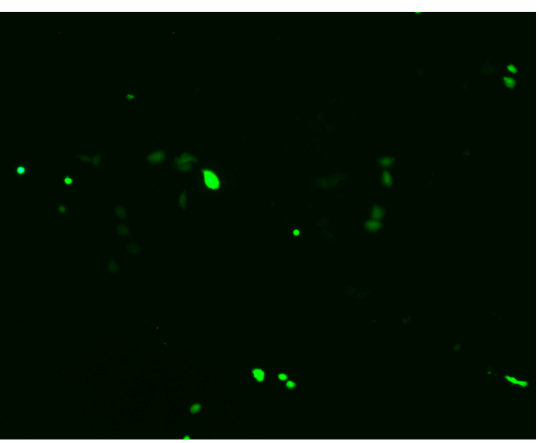

$\mathrm{Ch}_{2}-\mathrm{PEG}_{2000}-\mathrm{CLs}$

To further explain the differences in zeta potential and transfection efficacies of several cationic liposomes consisting of $\mathrm{Ch}_{2}-\mathrm{PEG}_{\mathrm{n}}$ with different molecular weights, XPS analysis was carried out of various $\mathrm{Ch}_{2}-\mathrm{PEG}_{\mathrm{n}}-\mathrm{CLs}$ and the schematic diagrams are shown in Figure 4. More oxygen atoms from ethylenedioxy groups of PEG were found on the surface of CLs with the increase of PEG molecular weight as shown in Figure 4B. The presence of PEG chains outside of CLs had the potential to shield the electronic charge, and decrease the zeta potential as shown in Figure 4A. However, $\mathrm{Ch}_{2}$-PEG600-CLs, with the shorter PEG chain, which could not shield the surface charge of liposomes, had a significant higher zeta potential than $\mathrm{Ch}_{2}-\mathrm{PEG}_{1000}-\mathrm{CLs}$ and $\mathrm{Ch}_{2}-\mathrm{PEG}_{2000}-\mathrm{CLs}$, which resulted in the increased transfection efficiency. The zeta potentials of $\mathrm{Ch}_{2}-\mathrm{PEG}_{1000}-\mathrm{CLs}$ and $\mathrm{Ch}_{2}-\mathrm{PEG}_{2000}-\mathrm{CLs}$ were comparable and might be due to the saturation of the shielding effect. $\mathrm{Ch}_{2}-\mathrm{PEG}_{1000}-\mathrm{CLs}$ and $\mathrm{Ch}_{2}-\mathrm{PEG}_{2000}-\mathrm{CLs}$ also showed comparable transfection efficiency due to similar zeta potential. 
Figure 4. Schematic diagram and XPS analysis of $\mathrm{Ch}_{2}-\mathrm{PEG}_{n}-\mathrm{CLs}$. (A) Ch segments of $\mathrm{Ch}_{2}-\mathrm{PEG}_{\mathrm{n}}$ anchored into the lipid bilayer of CLs. Due to the short PEG chain, Ch2-PEG600 did not effectively shield the charge of CLs. $\mathrm{Ch}_{2}-\mathrm{PEG}_{1000}$ and $\mathrm{Ch}_{2}-\mathrm{PEG}_{2000}$ decreased the positive charge by covering the surface of CLs. With longer PEG chains, Ch2-PEG2000 compressed the liposomal particle and therefore $\mathrm{Ch}_{2}-\mathrm{PEG}_{2000}-\mathrm{CLs}$ showed a smaller particle size; (B) XPS analysis demonstrated that more PEG segments were located on the surface of liposomes when PEG molecular weight increased.
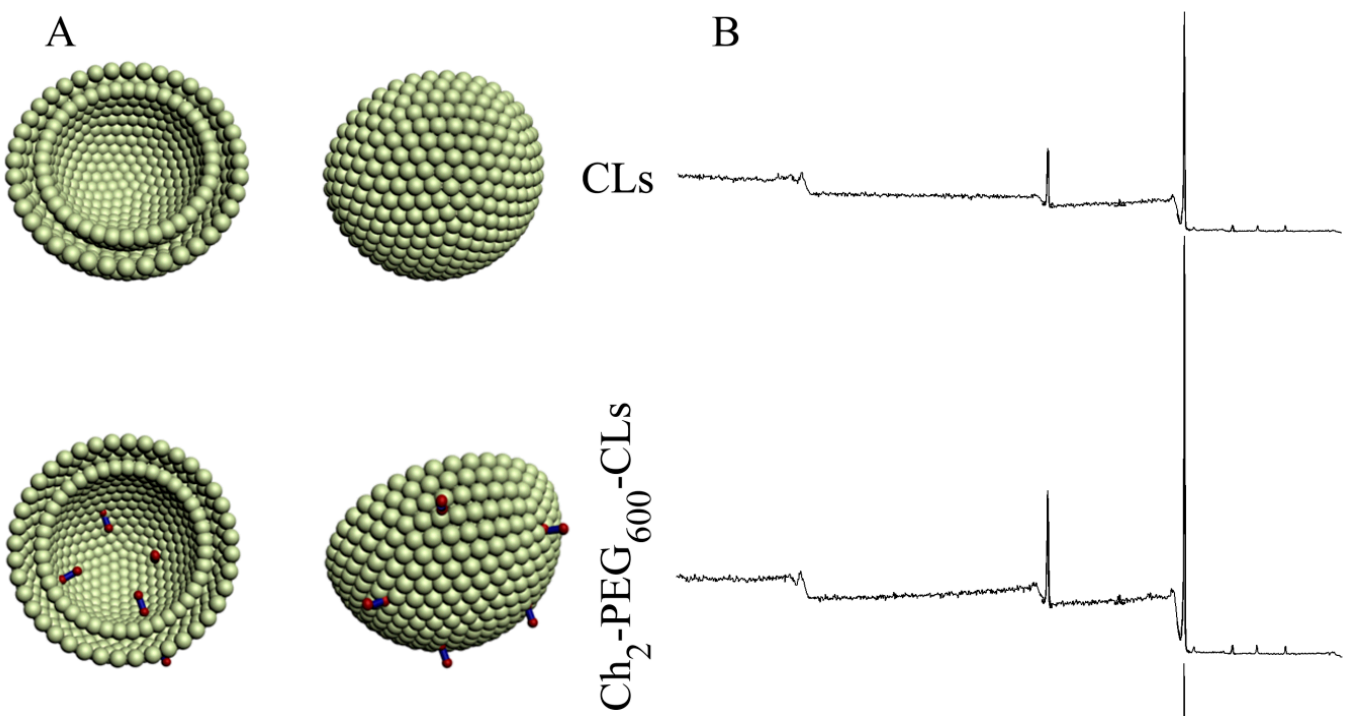

- $\mathrm{Ch}$

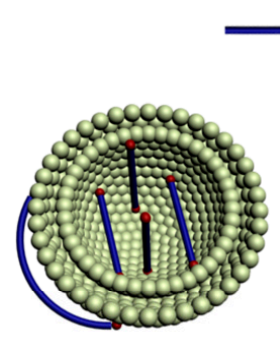

PEG
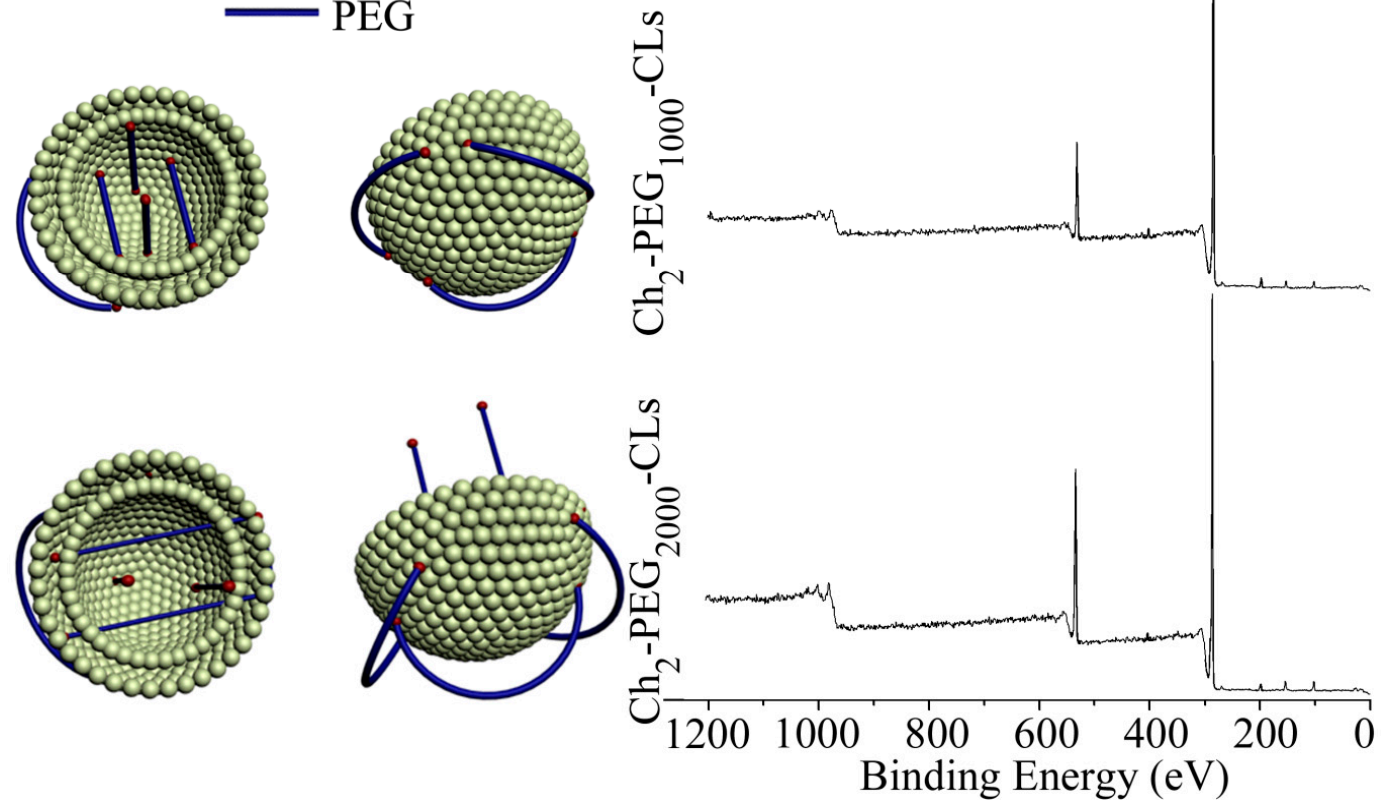

\subsection{Gene Transfection Efficiencies of F-Ch ${ }_{2}-P E G_{n}-C L s$ with Introduction of a Folate Ligand}

The gene delivery efficacy of $\mathrm{Ch}_{2}-\mathrm{PEG}_{\mathrm{n}}-\mathrm{CLs}$ was further examined by addition of a targeting moiety (folate ligand) in both folate-receptor (FR) overexpressing SKOV-3 cells and A549 cells with low expression of FR.

We previously demonstrated that SKOV-3 cells overexpress the folate receptor alpha [24]. The effects of folate ligand and its density on the transfection efficiencies of $\mathrm{Ch}_{2}-\mathrm{PEG}_{\mathrm{n}} \mathrm{CLs}$ in 
SKOV-3 cells are shown in Figure 5. For Ch2-PEG600-CLs, the transfection efficacy was close to 19\% without folate ligand modification. There was no special trend with the change of folate ligand ratio for F-Ch2-PEG600-CLs. Their transfection efficacies were all around 20\% (Figure 5A,D). In contrast, transfection efficiencies of F-Ch2-PEG1000-CLs were significantly elevated with the increase of folate ligand density $(p<0.001$, shown in Figure 5B,E). About $20 \%$ cells were transfected with $2.5 \%$ $\mathrm{F}_{-} \mathrm{Ch}_{2}-\mathrm{PEG}_{1000}-\mathrm{CLs}$, which was almost 3-fold of that for $\mathrm{Ch}_{2}-\mathrm{PEG}_{1000}-\mathrm{CLs}$ without folate modification. Similarly, 2.5\% F-Ch2-PEG $2000-\mathrm{CLs}$ had higher transfection efficiency than other $\mathrm{Ch}_{2}-\mathrm{PEG}_{1000}-\mathrm{CLs}$ as shown in Figure 5C,F. Therefore, the optimal ligand density should be screened when various PEG with different molecular weight was employed for preparing CLs in the future.

Figure 5. The effect of folate ligand densities in $\mathrm{F}-\mathrm{Ch}_{2}-\mathrm{PEG}_{\mathrm{n}} \mathrm{CLs}$ on transfection efficiencies (mean $\pm \mathrm{SD}, n=3$, *** $p<0.001$ ). (A-C) The transfection efficiencies of F-Ch2-PEG600-CLs, F-Ch2-PEG1000-CLs and F-Ch2-PEG2000-CLs. 0\%: $\mathrm{Ch}_{2}-\mathrm{PEG}_{n}-\mathrm{CLs}$ without folate ligand modification; $0.1 \%, 1.0 \%$ and $2.5 \%$ : $\mathrm{Ch}_{2}-\mathrm{PEG}_{\mathrm{n}}-\mathrm{CLs}$ modified by $0.1,1.0$ and 2.5 mol \% F-suc-PEG2000-Chol in total lipids, respectively; (D-F) The flow cytometry results of transfection by $\mathrm{F}-\mathrm{Ch}_{2}-\mathrm{PEG}_{\mathrm{n}}-\mathrm{CLs}$.
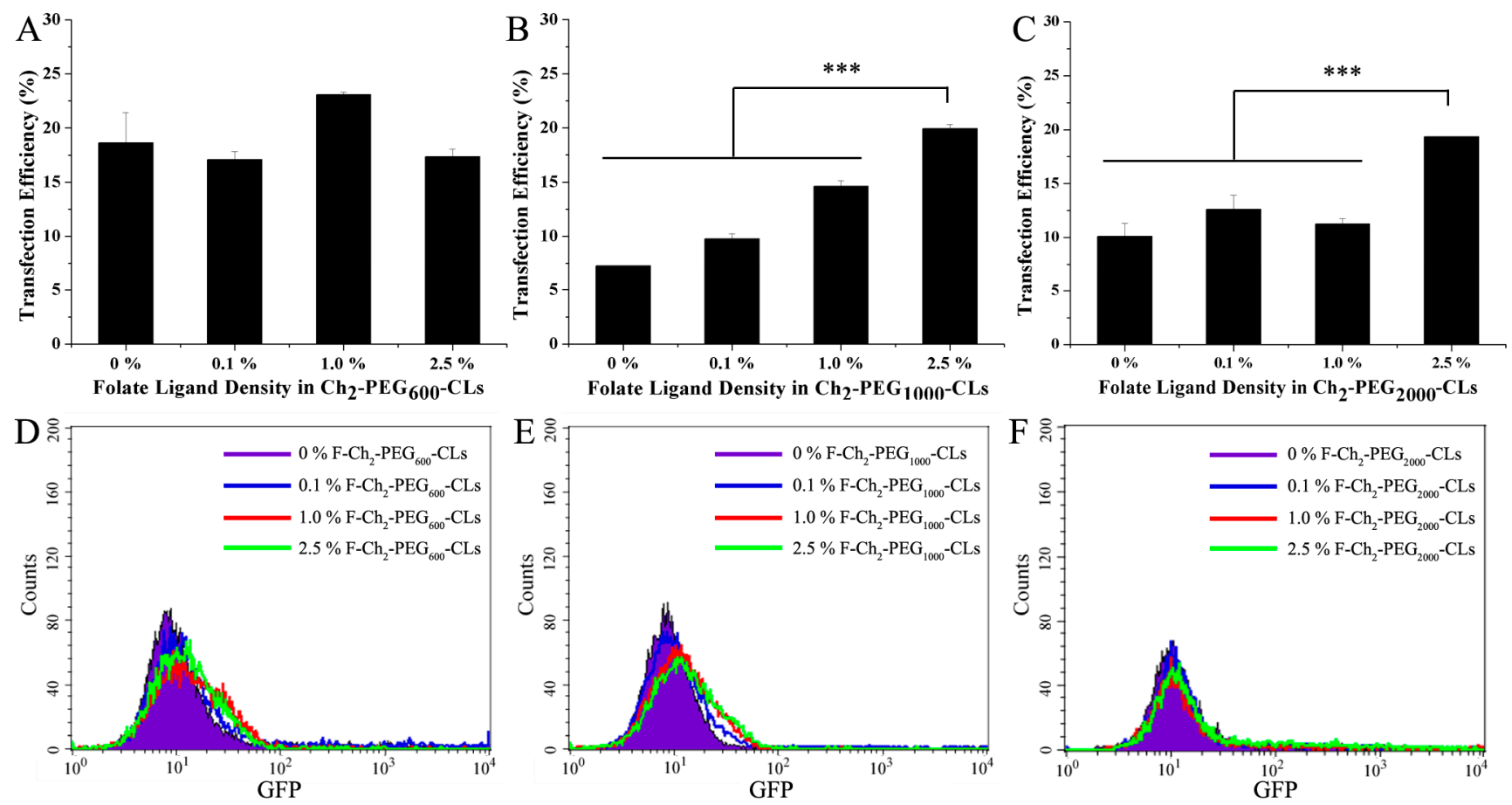

As shown in Figure 6A, folate receptor alpha is not expressed on A549 cells by folate receptor assay as previously reported [24]. When $\mathrm{Ch}_{2}-\mathrm{PEG}_{\mathrm{n}}-\mathrm{CLs}$ and $\mathrm{F}-\mathrm{Ch}_{2}-\mathrm{PEG}_{\mathrm{n}}-\mathrm{CLs}$ were used to transfect A549 cells, $\mathrm{F}-\mathrm{Ch}_{2}-\mathrm{PEG}_{\mathrm{n}}-\mathrm{CLs}$ did not significantly increase the transfection efficiency of $\mathrm{Ch}_{2}-\mathrm{PEG}_{\mathrm{n}}-\mathrm{CLs}$ as shown in Figure 6B. 
Figure 6. Folate receptor alpha expression and transfection efficiency on A549 cells. (A) Folate receptor alpha expression on A549 cells by flow cytometry and (B) The transfection efficiencies of $\mathrm{Ch}_{2}-\mathrm{PEG}_{\mathrm{n}}-\mathrm{CLs}$ and $\mathrm{F}-\mathrm{Ch}_{2}-\mathrm{PEG}_{\mathrm{n}}-\mathrm{CLs}$ on A549 cells.
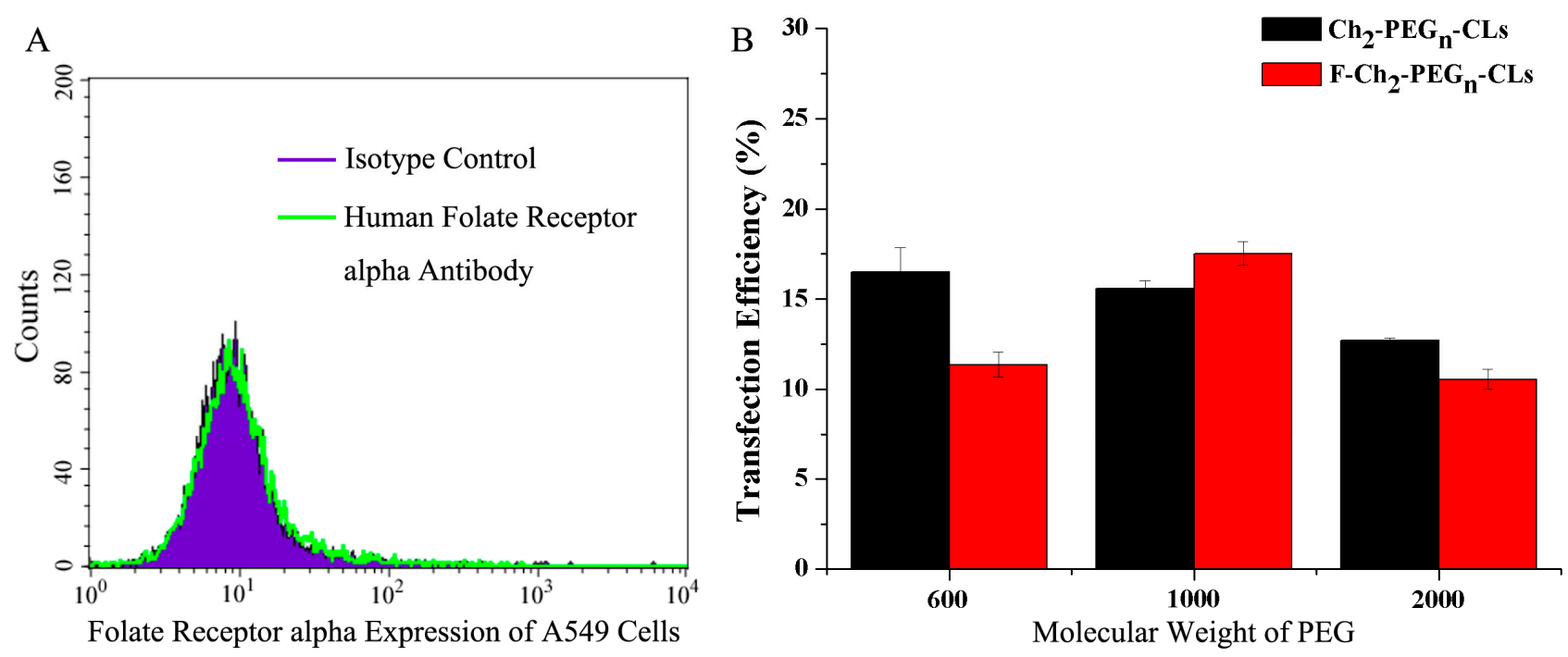

\subsection{Cytotoxicity Evaluation}

The cytotoxicities of $\mathrm{Ch}_{2}-\mathrm{PEG}_{\mathrm{n}}$ on SKOV-3 cells were shown in Figure 7A. The toxicities were concentration-dependent. After treatment for $24 \mathrm{~h}$, the half maximal inhibitory concentration (IC50) for $\mathrm{Ch}_{2}-\mathrm{PEG}_{600}, \mathrm{Ch}_{2}-\mathrm{PEG}_{1000}$ and $\mathrm{Ch}_{2}-\mathrm{PEG}_{2000}$ on SKOV-3 cells were about 78, 145 and $127 \mu \mathrm{M}$, respectively. $\mathrm{Ch}_{2}-\mathrm{PEG}_{600}$ was slightly more toxic to SKOV-3 cells than the other. However, even for $\mathrm{Ch}_{2}-\mathrm{PEG}_{600}$, the $\mathrm{IC}_{50}$ value was higher than other PEG-lipid conjugates that have been extensively used for drug and gene delivery [24,28]. Therefore, $\mathrm{Ch}_{2}-\mathrm{PEG}_{n}$ may be one kind of safe material for gene delivery.

The cytotoxicities of $\mathrm{Ch}_{2}-\mathrm{PEG}_{\mathrm{n}} \mathrm{CLs}$ on SKOV-3 cells were shown in Figure 7B. The cytotoxicities gradually decreased with the increase of PEG molecular weight. The IC50 values for CLs, $\mathrm{Ch}_{2}-\mathrm{PEG} 600-\mathrm{CLs}$, $\mathrm{Ch}_{2}$-PEG1000-CLs and $\mathrm{Ch}_{2}-\mathrm{PEG}_{2000}-\mathrm{CLs}$ were about 38, 100, 143 and $302 \mu \mathrm{M}$, respectively. 5 mol \% $\mathrm{Ch}_{2}-\mathrm{PEG}_{\mathrm{n}}$ significantly enhanced the safety of cationic liposomes when compared with CLs $(p<0.001)$. Therefore, employing $\mathrm{Ch}_{2}-\mathrm{PEG}_{\mathrm{n}}$ in preparation was an effective way to reduce the cytotoxicity of cationic liposomes. 
Figure 7. Cytotoxicity of $\mathrm{Ch}_{2}-\mathrm{PEG}_{\mathrm{n}}$ and $\mathrm{Ch}_{2}-\mathrm{PEG}_{\mathrm{n}}-\mathrm{CLs}$ on SKOV-3 cells by the MTT assay (Mean $\pm \mathrm{SD}, n=4-6$ ). (A) IC50 values for $\mathrm{Ch}_{2}-\mathrm{PEG}_{600}, \mathrm{Ch}_{2}-\mathrm{PEG}_{1000}$ and $\mathrm{Ch}_{2}-\mathrm{PEG}_{2000}$ were about 78, 145 and $127 \mu \mathrm{M}$, respectively; (B) IC50 values for CLs, Ch2-PEG600-CLs, $\mathrm{Ch}_{2}-\mathrm{PEG}_{1000}-\mathrm{CLs}$ and $\mathrm{Ch}_{2}-\mathrm{PEG}_{2000}-\mathrm{CLs}$ were about 38, 100, 143 and $302 \mu \mathrm{M}$, respectively. The cytotoxicity of CLs was reduced by introducing $\mathrm{Ch}_{2}-\mathrm{PEG}_{n}$ into $\mathrm{Ch}_{2}-\mathrm{PEG}_{\mathrm{n}} \mathrm{CLs}$.

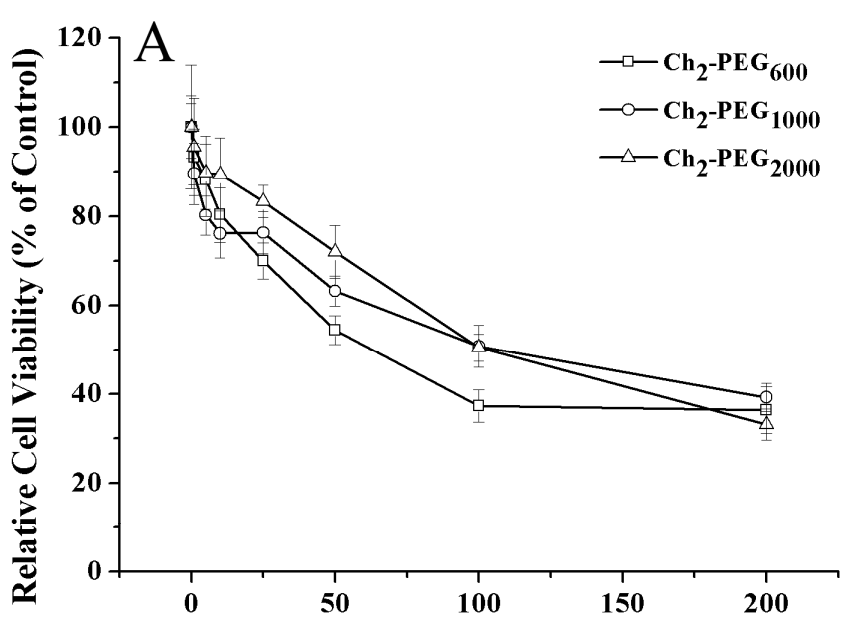

The Concentration of $\mathrm{Ch}_{2}-\mathrm{PEG}_{n}(\mu \mathrm{M})$

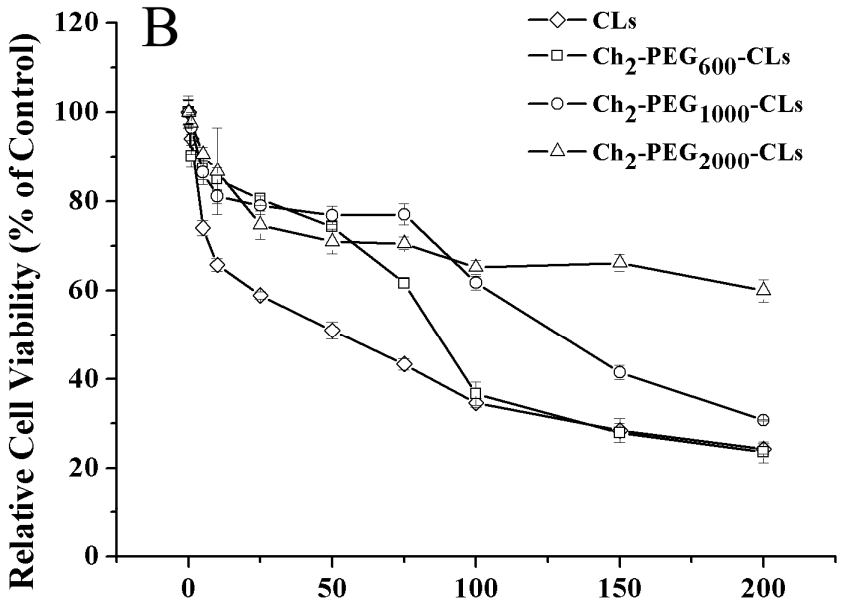

The Concentration of Liposomes $(\mu \mathrm{M})$

\section{Experimental Section}

\subsection{Materials}

Cholesterol (Ch) was obtained from Bio Life Science \& Technology Co., Ltd. (Shanghai, China). Poly (ethylene glycol) (PEG) [molecular weight 600 (PEG600), molecular weight 1000 (PEG 1000$)$ and molecular weight 2000 (PEG 2000$)$ ] and 3-(4, 5-Dimethyl-2-thiazolyl)-2, 5-diphenyl-2H-tetrazolium bromide (MTT) were purchased from Sigma-Aldrich (St. Louis, MO, USA). 1-(3-dimethylaminopropyl)-3-ethylcarbodiimide hydrochloride (EDCI) was provided by Accela ChemBio Co., Ltd. (Shanghai, China). 4-dimethylaminopyridine (DMAP) was obtained from AstaTech Pharma. Co., Ltd. (Chengdu, Sichuan, China). 1, 2-dioleoyl-3-trimethylammonium-propane (chloride salt) (DOTAP) was purchased from Avanti Polar Lipids Inc. (Alabaster, AL, USA). Folate-PEG-succinyl-cholesterol conjugate (F-PEG2000-suc-Ch) and mPEG-succinyl-cholesterol conjugate ( $\mathrm{mPEG}_{2000}$-suc-Ch) were synthesized and purified in the same procedures as those recorded in our previous publications [8,24]. Green fluorescent protein plasmid DNA (pDNA) was extracted according to the EndoFree Plasmid Purification Handbook (QIAGEN, Hilden, Germany). All the other reagents and solvents were of analytical grade and were used without further purification except for chloroform used for cationic liposomes preparation.

\subsection{Synthesis and Identification of $\mathrm{Ch}_{2}-P E G_{n}$}

\subsubsection{Synthesis of $\mathrm{Ch}_{2}-\mathrm{PEG}_{\mathrm{n}}$}

$\alpha, \omega$-Ch-modified PEGs $\left(\mathrm{Ch}_{2}-\mathrm{PEG}_{\mathrm{n}}\right)$ were synthesized according to scheme 1 . Firstly, Ch succinic anhydride ester (suc-Ch) was synthesized as described before [8]. In brief, $\mathrm{Ch}$, succinic anhydride and 
DMAP were dissolved in dichlormethane and stirred for $48 \mathrm{~h}$ at room temperature. After removing the solvent, the crude product was washed by acetic acid. White suc-Ch was obtained. Secondly, PEG (PEG600, PEG1000, or PEG 2000), suc-Ch, DMAP and EDCI were dissolved in chloroform. The mixture was refluxed for $72 \mathrm{~h}$, concentrated under vacuum, and purified on a silica-gel column eluting with dichlormethane and methanol. $\mathrm{Ch}_{2}-\mathrm{PEG} 600, \mathrm{Ch}_{2}-\mathrm{PEG}_{1000}$ and $\mathrm{Ch}_{2}-\mathrm{PEG}_{2000}$ were obtained.

\subsection{2. ${ }^{1} \mathrm{H}-\mathrm{NMR}$ and Mass Spectra of $\mathrm{Ch}_{2}-\mathrm{PEG}_{\mathrm{n}}$}

${ }^{1} \mathrm{H}-\mathrm{NMR}$ spectra of $\mathrm{Ch}_{2}-\mathrm{PEG}_{\mathrm{n}}$ were recorded on a Bruker ADVANCE ${ }^{\mathrm{III}}$ spectrometer $(400 \mathrm{MHz})$ (Billerica, MA, USA) at room temperature. $\mathrm{Ch}_{2}-\mathrm{PEG}_{600}, \mathrm{Ch}_{2}-\mathrm{PEG}_{1000}$ and $\mathrm{Ch}_{2}-\mathrm{PEG}_{2000}$ were dissolved in $\mathrm{CDCl}_{3}$ with tetramethylsilane as the internal standard. The mass spectra of $\mathrm{Ch}_{2}-\mathrm{PEG}_{\mathrm{n}}$ were measured using a Waters Q-TOF Premier (Milford, MA, USA) equipped with ion spray source and $\mathrm{N}_{2}$ as nebulization gas.

\subsubsection{Melting Point and Appearances}

Melting points of $\mathrm{Ch}_{2}-\mathrm{PEG}_{\mathrm{n}}, \mathrm{PEG}_{1000}, \mathrm{PEG}_{2000}$, $\mathrm{PEG}_{2000}-\mathrm{suc}-\mathrm{Ch}$, suc-Ch and $\mathrm{Ch}$ were determined using SGW X-4 melting point apparatus (Shanghai Precision \& Scientific Instrument CO., LTD., Shanghai, China). The appearances of the materials were recorded.

\subsection{Preparation and Characterization of Cationic Liposomes}

\subsubsection{Preparation of Liposomes}

$\mathrm{Ch}_{2}-\mathrm{PEG}_{\mathrm{n}}$-CLs were prepared by film dispersion method as described before [29]. In brief, DOTAP, $\mathrm{Ch}$ and $\mathrm{Ch}_{2}-\mathrm{PEG}_{\mathrm{n}}\left(\mathrm{Ch}_{2}-\mathrm{PEG}_{600}, \mathrm{Ch}_{2}-\mathrm{PEG}_{1000}\right.$ or $\left.\mathrm{Ch}_{2}-\mathrm{PEG}_{2000}\right)$ at different molar ratios were dissolved in chloroform. Then the organic solvent was removed from the lipids solution using a Büchi rotary evaporator. A thin film was formed and further dried under high vacuum for $6 \mathrm{~h}$ at room temperature. The lipid film was hydrated with 5\%(w/v) glucose solution and sonicated by a VCX130 Vibra-Cell (Sonics \& Materials Inc., Newtown, CT, USA) until a translucent lipid suspension was obtained. $\mathrm{Ch}_{2}-\mathrm{PEG}_{\mathrm{n}}-\mathrm{CLs}$ were formed. They were passed through a $0.22 \mu \mathrm{m}$ Millipore microporous membrane and stored at $4{ }^{\circ} \mathrm{C}$ until use.

CLs and mPEG-CLs (served as controls), folate modified $\mathrm{Ch}_{2}-\mathrm{PEG}_{\mathrm{n}}-\mathrm{CLs}$ (F-Ch2-PEG $\mathrm{F}-\mathrm{CLs}$, active targeted CLs) were prepared in the same way. CLs were made of DOTAP and Ch. mPEG-CLs were

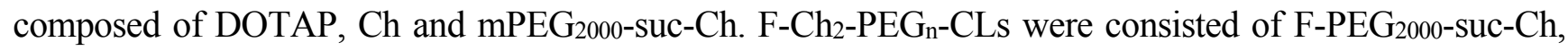
DOTAP, Ch and $\mathrm{Ch}_{2}-\mathrm{PEG}_{\mathrm{n}}$.

\subsubsection{Size and Zeta Potential Determination}

The mean particle size and zeta potential of the liposomes were measured by a Zetasizer Nano ZS ZEN 3600 (Malvern Instruments, Ltd., Malvern, Worcestershire, UK). The mean particle size was determined at a fixed angle of $173^{\circ}$. The zeta potential of $5 \mathrm{mg} / \mathrm{mL}$ liposome at $\mathrm{pH} 6.0$ was automatically calculated from the electrophoretic mobility at $25{ }^{\circ} \mathrm{C}$. All the experiments were performed in triplicate. 


\subsection{Cell Culture}

Human ovarian carcinoma SKOV-3 cell line and human lung carcinoma A549 cell line were obtained from American Type Culture Collection (ATCC). Cells were cultured as a monolayer in Dulbecco's Modified Eagles's Medium (DMEM, Gibco, Carlsbad, CA, USA) or Roswell Park Memorial Institute medium (RPMI)-1640 medium supplemented with 10\% fetal bovine serum, L-glutamine $(2 \mathrm{mmol} / \mathrm{L})$, penicillin $(100 \mathrm{units} / \mathrm{mL})$ and streptomycin $(100 \mu \mathrm{g} / \mathrm{mL})$ in a humidified atmosphere containing $5 \% \mathrm{CO}_{2}$ at $37^{\circ} \mathrm{C}$.

\subsection{In Vitro Transfection Experiments}

SKOV-3 or A549 cells were seeded on Costar 6-well plates (Corning Inc., Corning, NY, USA) at a density of $1.5 \times 10^{5}$ cells per well and cultured in DMEM medium or RPMI-1640 as described before [24]. $30 \mathrm{~min}$ prior to transfection, the culture medium was replaced by $800 \mu \mathrm{L}$ serum-free DMEM or RPMI-1640 in each well. Then $\mathrm{Ch}_{2}-\mathrm{PEG}_{\mathrm{n}}-\mathrm{CLs} / \mathrm{pEGFP}, \mathrm{CL} / \mathrm{pEGFP}, \mathrm{mPEG}-\mathrm{CLs} / \mathrm{pEGFP}$ or F-Ch $2-P^{-} G_{n}-C L s / p E G F P$ complexes $(200 \mu \mathrm{L}$, containing $1 \mu \mathrm{g}$ pDNA) was added to the wells respectively. Three wells were used for each lipoplex. After incubating for 5-6 h, cell culture medium was changed to DMEM or RPMI-1640 with serum and the cells were incubated for another 42-43 h. The transfected cells were observed under an inverted research microscope, Eclipse Ti (Nikon Corporation, Tokyo, Japan). Then they were trypsinized with $0.25 \%$ trypsin-EDTA, centrifuged and resuspended with PBS. The cell suspensions were analyzed by a FACS Calibur flow cytometer (BD Biosciences, San Jose, CA, USA) to determine the transfection efficiency of the complexes.

\subsection{Cytotoxicity of $C h_{2}-P E G_{n}$ and $C h_{2}-P E G_{n}-C L s$}

Cytotoxicity of $\mathrm{Ch}_{2}-\mathrm{PEG}_{n}$ was evaluated in the SKOV-3 cell line by MTT assay as described previously [30]. Briefly, cells were seeded on 96-well plates (Corning Inc., Corning, NY, USA) in $100 \mu \mathrm{L}$ medium at a density of $5 \times 10^{3}$ cells per well. After overnight incubation, another $100 \mu \mathrm{L}$ $\mathrm{Ch}_{2}-\mathrm{PEG}_{\mathrm{n}}$ solutions at various concentrations (ranged from 1 to $200 \mu \mathrm{M}$ ) were added to the wells. The cells were incubated for another $24 \mathrm{~h}$. Then $20 \mu \mathrm{L}$ MTT solution $(5 \mathrm{mg} / \mathrm{mL}$ in saline $)$ was added to each well. After culturing at $37{ }^{\circ} \mathrm{C}$ for $4 \mathrm{~h}$, the medium was removed. $160 \mu \mathrm{L}$ DMSO was added to each well to dissolve formazan crystals. The absorbance was measured at $570 \mathrm{~nm}$ on a Multiskan MK3 microplate reader (Thermo Fisher Scientific Inc., Waltham, MA, USA). Untreated cells were used as controls. The relative cell viability compared with control was calculated based on the following equation: Relative cell viability $(\%)=\left(A_{\text {treated }} / A_{\text {control }}\right) \times 100$.

\subsection{Statistical Analysis}

Statistical analysis was performed using Student's Independent-Samples $t$-Test on SPSS (V 19.0, IBM Corp., Armonk, NY, USA). All the statistical tests were two-sided. $p<0.05$ was considered as statistical significant difference. 


\section{Conclusions}

In this manuscript, a series of $\mathrm{Ch}_{2}-\mathrm{PEG}_{\mathrm{n}}$ at different PEG molecular weights $(600,1000$ and 2000) were successfully synthesized. $\mathrm{Ch}_{2}-\mathrm{PEG}_{\mathrm{n}}-\mathrm{CL}$ containing various $\mathrm{Ch}_{2}-\mathrm{PEG}_{\mathrm{n}}$ presented different particle size, zeta potential and in vivo transfection efficacy, and $\mathrm{Ch}_{2}-\mathrm{PEG}_{600}-\mathrm{CLs}$ exhibited the strongest GFP expression in SKOV3 cells due to its highest zeta potential. However, $\mathrm{Ch}_{2}-\mathrm{PEG}_{600}-\mathrm{CLs}$ also had the highest in vitro cytotoxicity. After introduction of a folate ligand, the targeting efficacies and optimized ligand densities of F-Ch2-PEGn-CLs still depended on the molecular weights of PEG. In sum, $\mathrm{Ch}_{2}-\mathrm{PEG}_{\mathrm{n}}-\mathrm{CLs}$ are promising carriers for gene delivery. The current work demonstrates the possibility of utilizing $\mathrm{Ch}_{2}-\mathrm{PEG}_{\mathrm{n}}$ for gene delivery, and a corresponding systematic investigation of this study would benefit the future development of $\mathrm{Ch}_{2}-\mathrm{PEG}_{\mathrm{n}}-\mathrm{CLs}$-based gene delivery systems.

\section{Acknowledgments}

This research was supported by the National Basic Research Program of China Grant 2010CB529900 and the National Natural Science Foundation of China Grant 81123003, and the Fundamental Research Funds for the Central Universities 2013SCU04A19.

\section{Author Contributions}

Cui-Cui Ma and Zhi-Yao He performed the experiments, analyzed the data and wrote the paper; Shan Xia, Li-Wei Hui and Han-Xiao Qin performed the experiments; Ke Ren and Jun Zeng wrote the paper; Ming-Hai Tang contributed reagents/materials/analysis tools; Xiang-Rong Song conceived and designed the experiments.

\section{Conflicts of Interest}

The authors declare no conflict of interest.

\section{References}

1. Ikonen, E. Cellular cholesterol trafficking and compartmentalization. Nat. Rev. Mol. Cell. Biol. 2008, 9, 125-138.

2. $\quad$ Lingwood, D.; Simons, K. Lipid rafts as a membrane-organizing principle. Science 2010, 327, 46-50.

3. He, Z.Y.; Wei, X.W.; Luo, M.; Luo, S.T.; Yang, Y.; Yu, Y.Y.; Chen, Y.; Ma, C.C.; Liang, X.; Guo, F.C.; et al. Folate-linked lipoplexes for short hairpin RNA targeting Claudin-3 delivery in ovarian cancer xenografts. J. Control. Release 2013, 172, 679-689.

4. Porter, C. J.; Trevaskis, N. L.; Charman, W.N. Lipids and lipid-based formulations: Optimizing the oral delivery of lipophilic drugs. Nat. Rev. Drug Discov. 2007, 6, 231-248.

5. Ma, Q.; Li, B.; Yu, Y.; Zhang, Y.; Wu, Y.; Ren, W.; Zheng, Y.; He, J.; Xie, Y.; Song, X.; et al. Development of a novel biocompatible poly(ethylene glycol)-block-poly( $\gamma$-cholesterol-L-glutamate) as hydrophobic drug carrier. Int. J. Pharm. 2013, 445, 88-92. 
6. Tang, J.; Zhang, L.; Liu, Y.; Zhang, Q.; Qin, Y.; Yin, Y.; Yuan, W.; Yang, Y.; Xie, Y.; Zhang, Z.; et al. Synergistic targeted delivery of payload into tumor cells by dual-ligand liposomes co-modified with cholesterol anchored transferrin and TAT. Int. J. Pharm. 2013, 454, 31-40.

7. Xu, L.; Wempe, M.F.; Anchordoquy, T.J. The effect of cholesterol domains on PEGylated liposomal gene delivery in vitro. Ther. Deliv. 2011, 2, 451-60.

8. Li, J.M.; He, Z.Y.; Yu, S.; Li, S.Z.; Ma, Q.; Yu, Y.Y.; Zhang, J.L.; Li, R.; Zheng, Y.; He, G.; et al. Micelles based on methoxy poly(ethylene glycol)cholesterol conjugate for controlled and targeted drug delivery of a poorly water soluble drug. J. Biomed. Nanotechnol. 2012, 8, 809-17.

9. Yu, Y.; He, Y.; Xu, B.; He, Z.; Zhang, Y.; Chen, Y.; Yang, Y.; Xie, Y.; Zheng, Y.; He, G.; et al. Self-assembled methoxy poly(ethylene glycol)cholesterol micelles for hydrophobic drug delivery. J. Pharm. Sci. 2013, 102, 1054-1062.

10. Oba, M.; Miyata, K.; Osada, K.; Christie, R.J.; Sanjoh, M.; Li, W.; Fukushima, S.; Ishii, T.; Kano, M.R.; Nishiyama, N.; et al. Polyplex micelles prepared from omega-cholesteryl PEG-polycation block copolymers for systemic gene delivery. Biomaterials 2011, 32, 652-663.

11. Xu, L.; Betker, J.; Yin, H.; Anchordoquy, T.J. Ligands located within a cholesterol domain enhance gene delivery to the target tissue. J. Control. Release 2012, 160, 57-63.

12. He, Z.Y.; Chu, B.Y.; Wei, X.W.; Li, J.; Edwards, C.K., 3rd; Song, X.R.; He, G.; Xie, Y.M.; Wei, Y.Q.; Qian, Z.Y. Recent development of poly(ethylene glycol)-cholesterol conjugates as drug delivery systems. Int. J. Pharm. 2014, 469, 168-178.

13. Meier, W.; Hotz, J.; GuntherAusborn, S. Vesicle and cell networks: Interconnecting cells by synthetic polymers. Langmuir 1996, 12, 5028-5032.

14. Carrion, C.; Domingo, J.C.; de Madariaga, M.A. Preparation of long-circulating immunoliposomes using PEG-cholesterol conjugates: Effect of the spacer arm between PEG and cholesterol on liposomal characteristics. Chem. Phys. Lipids 2001, 113, 97-110.

15. Rao, Z.; Taguchi, T. Spectroscopic studies on interactions between cholesterol-end capped polyethylene glycol and liposome. Colloids Surf. B Biointerfaces 2012, 97, 248-253.

16. Diec, K.H.; Sokolowski, T.; Wittern, K.P.; Schreiber, J.; Meier, W. New liposome gels by self organization of vesicles and intelligent polymers. Cosmet. Toiletries 2002, 117, 55-62.

17. Rao, Z.; Inoue, M.; Matsuda, M.; Taguchi, T. Quick self-healing and thermo-reversible liposome gel. Colloids Surf. B Biointerfaces 2011, 82, 196-202.

18. Perez, N.; Whitcombe, M.J.; Vulfson, E.N. Surface imprinting of cholesterol on submicrometer core-shell emulsion particles. Macromolecules 2001, 34, 830-836.

19. Petersen, H.; Fechner, P.M.; Martin, A.L.; Kunath, K.; Stolnik, S.; Roberts, C.J.; Fischer, D.; Davies, M.C.; Kissel, T. Polyethylenimine-graft-poly(ethylene glycol) copolymers: Influence of copolymer block structure on DNA complexation and biological activities as gene delivery system. Bioconjug. Chem. 2002, 13, 845-854.

20. Savic, R.; Luo, L.; Eisenberg, A.; Maysinger, D. Micellar nanocontainers distribute to defined cytoplasmic organelles. Science 2003, 300, 615-618.

21. Wang, Y.; Ke, C.Y.; Beh, C.W.; Liu, S.Q.; Goh, S.H.; Yang, Y.Y., The self-assembly of biodegradable cationic polymer micelles as vectors for gene transfection. Biomaterials 2007, 28, 5358-5368. 
22. Zhang, X.; Pan, S.R.; Hu, H.M.; Wu, G.F.; Feng, M.; Zhang, W.; Lu, X. Poly(ethylene glycol)-block-polyethylenimine copolymers as carriers for gene delivery: Effects of PEG molecular weight and PEGylation degree. J. Biomed. Mater. Res. A 2008, 84A, 795-804.

23. Haak, C.S.; Bhayana, B.; Farinelli, W.A.; Anderson, R.R.; Haedersdal, M. The impact of treatment density and molecular weight for fractional laser-assisted drug delivery. J. Control. Release 2012, $163,335-341$.

24. He, Z.; Yu, Y.; Zhang, Y.; Yan, Y.; Zheng, Y.; He, J.; Xie, Y.; He, G.; Wei, Y.; Song, X. Gene delivery with active targeting to ovarian cancer cells mediated by folate receptor $\alpha$. J. Biomed. Nanotechnol. 2013, 9, 833-844.

25. Heyes, J.; Hall, K.; Tailor, V.; Lenz, R.; MacLachlan, I. Synthesis and characterization of novel poly(ethylene glycol)-lipid conjugates suitable for use in drug delivery. J. Control. Release 2006, 112, 280-290.

26. Gimpl, G.; Gehrig-Burger, K. Probes for studying cholesterol binding and cell biology. Steroids 2011, 76, 216-231.

27. Photos, P.J.; Bacakova, L.; Discher, B.; Bates, F.S.; Discher, D.E. Polymer vesicles in vivo: Correlations with PEG molecular weight. J. Control. Release 2003, 90, 323-334.

28. Han, X.; Liu, J.; Liu, M.; Xie, C.; Zhan, C.Y.; Gu, B.; Liu, Y.; Feng, L.L.; Lu, W.Y. 9-NC-loaded folate-conjugated polymer micelles as tumor targeted drug delivery system: Preparation and evaluation in vitro. Int. J. Pharm. 2009, 372, 125-131.

29. He, Z.; Zheng, X.; Wu, X.; Song, X.; He, G.; Wu, W.; Yu, S.; Mao, S.; Wei, Y. Development of glycyrrhetinic acid-modified stealth cationic liposomes for gene delivery. Int. J. Pharm. 2010, 397, 147-154.

30. Song, X.R.; Zheng, Y.; He, G.; Yang, L.; Luo, Y.F.; He, Z.Y.; Li, S.Z.; Li, J.M.; Yu, S.; Luo, X.; et al . Development of PLGA nanoparticles simultaneously loaded with vincristine and verapamil for treatment of hepatocellular carcinoma. J. Pharm. Sci. 2010, 99, 4874-4879.

(C) 2014 by the authors; licensee MDPI, Basel, Switzerland. This article is an open access article distributed under the terms and conditions of the Creative Commons Attribution license (http://creativecommons.org/licenses/by/4.0/). 